\title{
Phytochemical Analysis and Antioxidant Activity Determination on Crude Extracts of Melodinus eugeniifolus Barks and Leaves from Malaysia
}

\author{
Yao Lu*, Teng-Jin Knoo, Christophe Wiart \\ School of Pharmacy, Faculty of Science, University of Nottingham, Malaysia Campus, Semenyih, Selongar, \\ Malaysia \\ Email: $\underline{\text { emilyly@126.com, }{ }^{*} \text { khyx2lyo@nottingham.edu.my }}$
}

Received 6 May 2014; revised 9 June 2014; accepted 26 June 2014

Copyright (C) 2014 by authors and Scientific Research Publishing Inc.

This work is licensed under the Creative Commons Attribution International License (CC BY).

http://creativecommons.org/licenses/by/4.0/

(c) (i) Open Access

\begin{abstract}
Six different extracts of Melodinus eugeniifolus (a very rare medical plant belonging to Apocynaceae) leaves and barks were screened for their phytochemical composition, and free radical scavenging activities. Three different methods were used to test the antioxidant activity for extracts which include FRAP assay (Ferric reducing antioxidant potential), DPPH radical scavenging assay (1,1-diphenyl-2-picryl hydrazyl radical reducing power methods), and $\beta$-carotene bleaching assay. Among the different extracts tested, the ethanol extract of barks showed significant radical scavenging activities. Phytochemical analysis of the extracts revealed that the radical scavenging activities are mainly due to the presence of alkaloids, cardiac glycosides, sterols, steroids and flavonoids. The results obtained suggest that Melodinus eugeniifolus could be exploited in the management of various diseases like cancer, cardiovascular diseases and infection diseases. Highlights: Melodinus eugeniifolus, a very rare medical plant from South Asian rain forest which may be a potential drug for many diseases is first reported about its phytochemical characteristics and antioxidant activity by different methods.
\end{abstract}

\section{Keywords}

Antioxidant Activity, DPPH Assay, FRAP Assay, $\beta$-Carotene Bleaching Assay, Phytochemical Analysis, Apocynaceae, Melodinus eugeniifolus

\footnotetext{
${ }^{*}$ Corresponding author.
} 


\section{Introduction}

The term "antioxidant" refers to any substance that delays, prevents or removes oxidative damage to a target molecule [1]. Antioxidants comprise a broad and heterogeneous family of compounds that interfere with the oxidation of any oxidizable substrate [2]. Antioxidants scavenge and prevent the formation of free radicals such as superoxides which accumulate in the body at a rate of 1\% per day at rest and increases 10-fold during body exertion [3]. In fact, within the past decade, a considerable body of evidence has accumulated in support of the view that natural products with antioxidant properties might be beneficial to health and several in vitro antioxidant techniques have been developed such as FRAP, DPPH and $\beta$-carotene bleaching assay. Indeed, one ought to perform several methods to accurately estimate the antioxidant potential of a sample as it should cover the mechanisms of different reactions [4]. In line with this contention, we analyzed our samples with three different assays to accommodate different antioxidant mechanisms.

Several studies have shown that the mechanism underlying polar antioxidant involves reactions with the hydroxyl $(\mathrm{OH})$ group present in phenolics. Indeed, phenolics are composed of one or more aromatic rings bearing one or more hydroxyl groups and are therefore potentially able to quench free radicals by forming stabilized phenoxyl radicals [5] and most of the current antioxidants isolated so far from flowering plants are simple phenolic compounds which owe their properties to the mere fact that their aromatic hydroxyl moieties react with free radicals.

Melodinus sp. a very rare medicinal plant belongs to the family of Apocynaceae. This family consists of 424 genera and 1500 species of trees. In the Asia-Pacific region, about 20 species of Apocynaceae are used to treat diseases like cancer and cardiovascular diseases. Furthermore, there are almost no pharmacological and phytochemical studies in genera Melodinus. This study was undertaken to screen the phytochemical composition, antimicrobial, antioxidant and anticancer activity of different extracts of Melodinus sp. (Apocynaceae Juss.).

As part of an ongoing study to identify antioxidants from medicinal plants, we have previously extracted hexane, chloroform and ethanol. With this premise in mind we seek to examine the antioxidant potencies and principle of the Malaysian medicinal tree Melodinus eugeniifolus.

\section{Materials and Methods}

\subsection{Plant Material}

The leaves and barks of Melodinus eugeniifolus Wall. ex G.Don were collected from one individual tree in August 2012 from Bukit Putih, Selongar, Malaysia ( $\left.3^{\circ} 5^{\prime} 24^{\prime \prime N}, 101^{\circ} 46^{\prime} 0^{\prime \prime} \mathrm{E}\right)$. The leaves and barks are air dried and grinded into pulverized powders by a medicinal grinder.

\subsection{Chemicals and Reagents}

1,1-diphenyl-2-picrylhydrazyl (DPPH), 2,4,6-Tris(2-pyridyl)-1,3,5-triazine (TPTZ) and $\beta$-carotene were phased from Aldrich. Quercetin was purchased from Sigma, Germany. Gallic acid was purchased from Tokyo Chemical Industry, Japan. Sodium chloride, ascobic acid, ferric chloride, and ferrous sulphate were phased from System. Acetic acid, DMSO, sulfuric acid and hydrochloric acid were phased from R \& M Marketing, Essex UK. Hexane, chloroform, methanol and ethanol were phased from MERCK. All the chemicals were of analytical grade.

\subsection{Extraction}

Dried and grinded samples of barks $(2.5 \mathrm{~kg})$ and leaves $(0.3 \mathrm{~kg})$ were respectively soaked in hexane with the ratio of 1:3 for 72 hours, parts of sample to solvent for 2 hours in a $60^{\circ} \mathrm{C}$ water bath, then filter and concentrated with a rotary evaporator (Buchi, R-200 Switzerland). This was repeated 3 times. Thereafter, the barks and leaves were left to air dry completely for 3 days before repeating the whole process with chloroform, and then ethanol, respectively. The yield for the hexane, chloroform and ethanol extracts of leaves were 5.0\%, 3.9\% and 3.4\%, respectively. The yield for the hexane, chloroform and ethanol extracts of barks were $1.0 \%, 0.67 \%$ and $0.56 \%$, respectively. The crude extracts were kept at $-20^{\circ} \mathrm{C}$ until further use.

\subsection{Preliminary Phytochemical Analysis}

Qualitative phytochemical analysis of the crude extract was determined as follows [6] [7]. 
Alkaloids. $200 \mathrm{mg}$ of extract was dissolved in $10 \mathrm{~mL}$ of methanol and heated on a boiling water bath with $2 \mathrm{~N}$ $\mathrm{HCl}(5 \mathrm{~mL})$. After cooling, the mixture was filtered and the filtrate was divided into two equal portions. One portion was treated with a few drops of Dragendorf reagent and the other with equal amounts of Wagner's reagent. The samples were then observed for the presence of turbidity or precipitation. A $(+)$ score was recorded if the reagent produces only a slight opaqueness; a (++) score was recorded if a definite turbidity, but no flocculation was observed, and a (+++) score was recorded if a definite heavy precipitate or flocculation was produced [6] [7].

Dragendorf reagent. Solution A: Bismuth nitrate $(0.17 \mathrm{~g})$ in acetic acid $(2 \mathrm{~mL})$ and water $(8 \mathrm{~mL})$. Solution B: $\mathrm{KI}(4 \mathrm{~g})$ in acetic acid $(10 \mathrm{~mL})$ and water $(20 \mathrm{~mL})$. Mix Solutions. A and B and dilute to $100 \mathrm{~mL}$ with water.

Wagner's reagent. $1.27 \mathrm{~g} \mathrm{I}_{2}$ (sublimed) and $2 \mathrm{~g}$ KI was dissolved in $20 \mathrm{~mL}$ water, and water is made up to 100 $\mathrm{mL}$. A brown precipitate indicates the presence of alkaloids.

Flavonoids. $40 \mathrm{mg}$ extract was dissolved in $2 \mathrm{~mL}$ ethanol and filtered. The filtrate was treated with a few drops of concentrated $\mathrm{HCl}$ and magnesium ribbons or turnings $(0.5 \mathrm{~g})$. The presence of flavonoids was indicative if pink or magenta-red color developed within 3 minutes [6] [7].

Saponins. About $2.5 \mathrm{~g}$ of the plant material was extracted with boiling water. After cooling, the extract was shaken vigorously to froth and was then allowed to stand for 15 - 20 minutes and classified for saponin content as follows: (no froth = negative; froth less than $1 \mathrm{~cm}$ = weakly positive; froth $1-2 \mathrm{~cm}$ high = positive; and froth greater than $2 \mathrm{~cm}$ high = strongly positive) [6] [7].

Tannins. About $200 \mathrm{mg}$ of extract was dissolved in $10 \mathrm{~mL}$ of hot distilled water and filter. The solution was divided in three test tubes. To the first $0.9 \%$ solution of sodium chloride was added, to the second $0.9 \%$ sodium chloride and $1 \%$ gelatine solution were added, and to the third ferric chloride $\left(\mathrm{FeCl}_{3}\right)$ was added. Formation of a precipitate in the second treatment suggests the presence of tannins, and a positive response after addition of $\mathrm{FeCl}_{3}$ to the third portion which will result in a characteristic blue, blue-black, green or blue-green color supports this inference [6] [7].

Sterols (Salkowski reaction). $40 \mathrm{mg}$ of extract was dissolved in $2 \mathrm{~mL}$ of chloroform and filtered. The filtrate was then added to $1 \mathrm{~mL}$ of concentrated $\mathrm{H}_{2} \mathrm{SO}_{4}$ (sulfuric acid). The presence of sterols was indicated by the 2 phase formation with a red color in the chloroform phase [6] [7].

Cardiac glycosides (Keller-Kiliani test). $40 \mathrm{mg}$ extract was dissolved in $2 \mathrm{~mL}$ ethanol and filtered. The filtrate was treated with $1 \mathrm{~mL}$ glacial acetic acid, then added to a few drops of $\mathrm{FeCl}_{3}$ and concentrated $\mathrm{H}_{2} \mathrm{SO}_{4}$. The presence of cardiac glycosides was indicated by the green-blue color indicates [6] [7].

\subsection{Ferric Reducing Antioxidant Potential Assay (FRAP Assay)}

The antioxidant capacity was determined following the procedure described by Benzie and Strain [8] with slight modifications. The FRAP reagent was prepared fresh by adding $10 \mathrm{mM}$ of 2,4,6-Tris(2-pyridyl)-1,3,5-triazine (TPTZ) (dissolved with $40 \mathrm{mM}$ of $\mathrm{HCl}$ ), $20 \mathrm{mM}$ of $\mathrm{FeCl}_{3}$ in water and $300 \mathrm{mM}$ of acetate buffer (pH 3.6) in ratio of 1:1:10. A blank containing sample and solvents only was used for colour correction. The 96-well plates were then incubated at $37^{\circ} \mathrm{C}$ for 90 minutes before absorbance were recorded at $593 \mathrm{~nm}$. Vitamin C (L-ascorbic acid), gallic acid and quercetin were used as antioxidant standards and positive controls. The absorbance of the samples were compared to a $\mathrm{FeSO}_{4}$ standard curve and the FRAP values were expressed as Ferrous Equivalent (FE), the concentration of extract or chemical which gives the same absorbance as $1 \mathrm{mmol}$ ferrous ion.

\subsection{DPPH Radical Scavenging Assay (DPPH Assay)}

The DPPH assay, as previously reported by Alothman et al. [9] and Juan-Badaturuge et al. [10], was employed to determine the radical scavenging activity of the plant extracts. Aliquots of plant extract dissolved in dimethyl sulfoxide (DMSO) were plated out in triplicate in a 96-well microtiter plate. The methanolic DPPH $(50 \mu \mathrm{M})$ solution (Aldrich) was added to alternating column of the test samples and methanol for control of test samples, in the remaining columns. The plate was shaken for 2 minutes and incubated for 20 minutes in the dark at $37^{\circ} \mathrm{C}$ water bath. The percentage decolourisation was obtained spectrophoto-metrically at $517 \mathrm{~nm}$ using the Thermo Scientific Varioskan Flash microtiter plate reader, linked to a computer equipped with (SkanIt Software 2.4.3). Percentage decolourisation was plotted against the concentration of the sample, and the $\mathrm{EC}_{50}$ values were determined using Prism 5.00 software. Vitamin C (L-ascorbic acid), gallic acid and quercetin were used as antioxidant standards and positive controls. At least, three independent teses were performed for each sample. The 
DPPH absorbance decreases with an increase in DPPH radical scavenging activity. Results were expressed as IC $_{50}$ concentration where $50 \%$ inhibition of the DPPH radical is obtained. This activity is given as percent DPPH radical scavenging, which is calculated with the equation:

$$
\text { DPPH radical scavenging activity }(\%)=\left[\left(A b s_{\text {control }}-A b s_{\text {sample }}\right) /\left(A b s_{\text {control }}\right)\right] \times 100
$$

where $A b s_{\text {control }}$ is absorbance of DPPH radical + methanol and $A b s_{\text {sample }}$ is absorbance DPPH radical + sample extract/standard.

\section{7. $\beta$-Carotene Bleaching Assay}

To appraise lipid peroxidation activity of the samples, $\beta$-carotene bleaching assay is carried out according to the method of Barreira et al. [1], Velioglu et al. [11] and Lu \& Foo [12].

$\beta$-carotene was dissolved with chloroform, and linoleic acid and Tween 80 were added in. After the chloroform had been evaporated, distilled water was added in to form an emulsion. The emulsion is tested with different concentrations of samples and standards. Incubations were done at $50^{\circ} \mathrm{C}$ for 4 hours. The oxidation of $\beta$-carotene emulsion was monitored by measuring the absorbance at $490 \mathrm{~nm}$ via a Dynex microplate reader. Degradation rates are calculated according to first order kinetics. This activity is calculated with the equations below:

$$
\text { Degradation rate }(\mathrm{DR})=\ln a / b \times 1 / t
$$

where by " $a$ " is the initial absorbance, " $b$ " is the absorbance at $240 \mathrm{~min}$ and t is the whole test time (240 min).

The antioxidant activity was presented as percent inhibition using the following formula:

$$
\text { Antioxidant activity }(\%)=(\text { DR control }- \text { DR sample }) / D R \text { control } \times 100 \text {. }
$$

IC $_{50}$ : concentration where $50 \%$ inhibition of the $\beta$-Carotene bleaching radical is obtained.

\subsection{Statistical Analysis}

Concentration-response curves were calculated using the Prism software package 5.00 for Windows, GraphPad Software, San Diego, Calif, USA, http://www.graphpad.com/ (GraphPad, San Diego, Calif, USA) and data were reported as mean and SD values obtained froma minimum of three determinations. Nonlin-ear best fit was plotted with SD and 95\% confidence interval.

\section{Results and Discussion}

\subsection{Preliminary Phytochemical Analysis}

Phytochemical analysis of Melodinus eugeniifolus (Table 1) revealed presence of alkaloids, flavonoids, sterols, steroids and cardiac glycosides in all the crude extracts. Saponins were detected in all the chloroform and ethanol extracts. Tannins were not detected in any of crude extract.

Table 1. Preliminary phytochemical analysis of the crude extracts of Melodinus eugeniifolus.

\begin{tabular}{ccccccc}
\hline Sample & Alkaloids & Flavonoids & Saponins & Tannins & Sterols / Steroids & Cardiac glycosides \\
\hline $\mathrm{BH}$ & ++ & ++ & - & - & ++ & +++ \\
$\mathrm{BC}$ & ++ & + & + & - & ++ & ++ \\
$\mathrm{BE}$ & ++ & + & + & - & ++ & ++ \\
$\mathrm{LH}$ & ++ & + & + & - & ++ & ++ \\
$\mathrm{LC}$ & ++ & + & + & ++ & ++ & ++ \\
$\mathrm{LE}$ & + & + & + & - & + & ++ \\
\hline
\end{tabular}

BH: bark hexane extract, BC: bark chloroform extract, BE: bark ethanol extract, LH: leaf hexane extract, LC: leaf chloroform extract, LE: leaf ethanol extract, and -: negative, +: trace, ++: positive, and +++: strongly positive. 


\subsection{Ferric Reducing Antioxidant Potential Assay (FRAP Assay)}

The method is based on the principle of the reduction of the ferric-tripyridyltriazine complex to the ferrous form, upon which an intense blue color develops, and the change of absorbance is measured at $593 \mathrm{~nm}$ (kinetic method) [8]. The FRAP assay is employed to estimate the antioxidant capacity of samples in vitro. In this test, the result (Figure 1) revealed that a good linearity of ferrous sulfate $\left(\mathrm{FeSO}_{4}\right)$ and was obtained within the range of 0.15 $1.40 \mathrm{mM}\left(\mathrm{R}^{2}=0.9999\right)$. The antioxidant activities were highest for the ethanol extract of barks (Table 2) $(2.40 \pm$ $0.001 \mathrm{mmol} / \mathrm{g})$, even better than gallic acid $(2.17 \pm 0.002 \mathrm{mmol} / \mathrm{g})$, followed by the ethanol extract of leaves $(1.28 \pm 0.002 \mathrm{mmol} / \mathrm{g})$ and the chloroform extract of barks $(1.22 \pm 0.002 \mathrm{mmol} / \mathrm{g})$.

\subsection{DPPH Radical Scavenging Assay (DPPH Assay)}

DPPH is a stable free radical which accepts an electron or hydrogen radical to become a stable diamagnetic molecule, which is widely used to investigate radical-scavenging activity. In DPPH radical scavenging assay, antioxidants react with DPPH, and convert it to yellow coloured a, a-diphenyl- $\beta$-picryl hydrazine. The degree of diacolouration indicates the radical-scavenging potential of the antioxidant activities [13]. In this test, the ethano

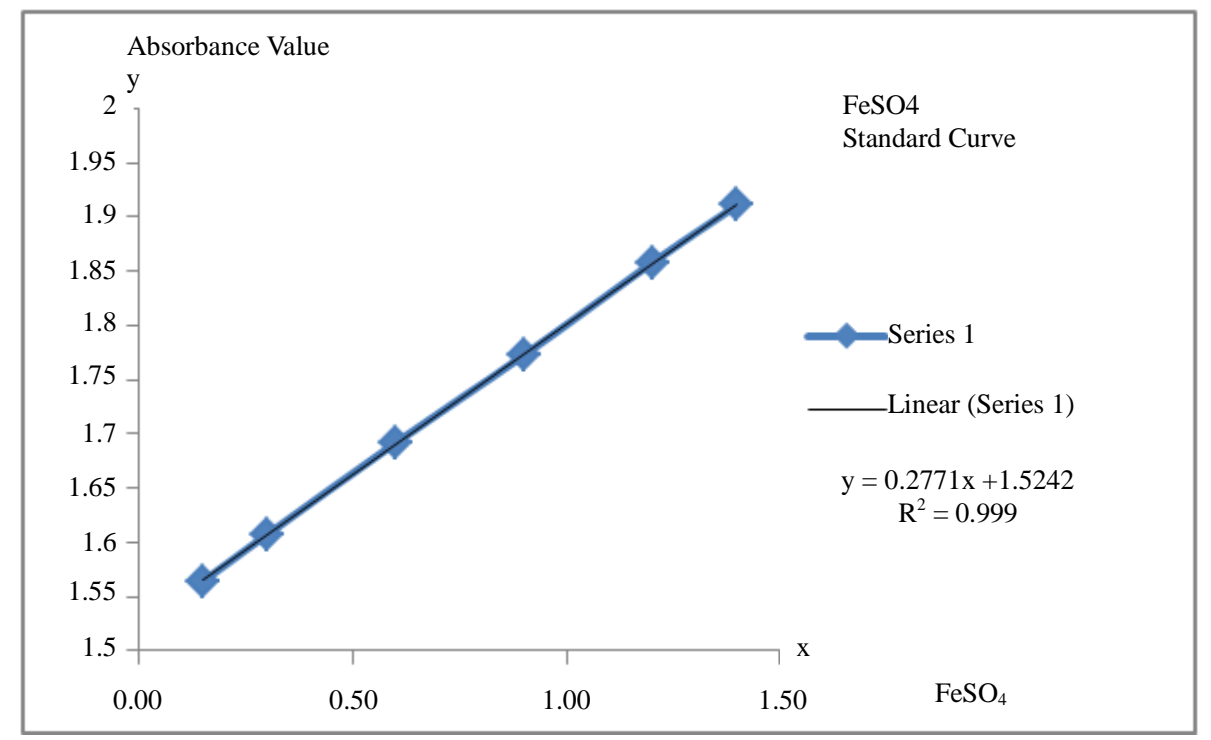

Figure 1. $\mathrm{FeSO}_{4}$ Standard curve. Standard equation: $\mathrm{y}=0.2771 \mathrm{x}+1.5242 ; \mathrm{R}^{2}=0.9999$.

Table 2. Ferric reducing antioxidant capacity of extract.

\begin{tabular}{cccc}
\hline SAMPLE & Concentration $(\mathrm{mg} / \mathrm{ml})$ & Ferrous Equivalent $(\mathrm{mM})$ & Antioxidant Capacity $(\mathrm{mmol} / \mathrm{g})$ \\
\hline BH & 1.00 & $0.77 \pm 0.001$ & $0.77 \pm 0.001$ \\
BC & 0.50 & $0.61 \pm 0.001$ & $1.22 \pm 0.002$ \\
BE & 0.50 & $1.20 \pm 0.001$ & $2.40 \pm 0.001$ \\
LH & 1.00 & $0.24 \pm 0.001$ & $0.24 \pm 0.001$ \\
LC & 0.50 & $0.44 \pm 0.001$ & $0.88 \pm 0.002$ \\
LE & 0.50 & $0.64 \pm 0.001$ & $1.28 \pm 0.002$ \\
AA & 0.25 & $1.20 \pm 0.001$ & $4.79 \pm 0.002$ \\
GA & 0.25 & $0.54 \pm 0.001$ & $2.17 \pm 0.002$ \\
QC & 0.25 & $1.39 \pm 0.001$ & $5.56 \pm 0.002$ \\
\hline
\end{tabular}

BH: bark hexane extract, BC: bark chloroform extract, BE: bark ethanol extract, LH: leaf hexane extract, LC: leaf chloroform extract, LE: leaf ethanol extract, AA: Ascorbic Acid, GA: Gallic Acid, QC: Quercetin. 
extract of barks and leaves exihibited profound antioxidant activities (Table 3, Table 4, Figure 2). The antioxidant activities were highest for the ethanol extract of barks ( $\mathrm{IC}_{50}: 1.90 \pm 0.01 \mu \mathrm{g} / \mathrm{mL}$ ), followed by the ethanol extract of leaves ( $\mathrm{IC}_{50}: 11.30 \pm 0.02 \mu \mathrm{g} / \mathrm{mL}$ ) and the chloroform extract of leaves ( $\mathrm{IC}_{50}: 19.90 \pm 0.01 \mu \mathrm{g} / \mathrm{mL}$ ) (Table 3, Table 4, Figure 2).

\section{4. $\beta$-Carotene Bleaching Assay}

The $\beta$-Carotene bleaching method is based on the loss of the yellow colour of b-carotene due to its reaction with radicals which are formed by linoleic acid oxidation in an emulsion. The rate of $\beta$-carotene bleaching can be slowed down in the presence of antioxidants. This fact is used in the antioxidant activity evaluation in comparison with ascorbic acid (vitamin C), gallic acid and quercetin [11] [12]. In this assay, the antioxidant activities were highest for the ethanol extract of barks ( $\mathrm{IC}_{50}: 9.90 \pm 0.01 \mu \mathrm{g} / \mathrm{mL}$ ), even better than gallic acid ( $\mathrm{IC}_{50}: 10.50$ $\pm 0.02 \mu \mathrm{g} / \mathrm{mL}$ ) and quecetin ( $\mathrm{IC}_{50}: 25.10 \pm 0.01 \mu \mathrm{g} / \mathrm{mL}$ ), followed by the ethanol extract of leaves $\left(\mathrm{IC}_{50}: 24.30 \pm\right.$ $0.02 \mu \mathrm{g} / \mathrm{mL}$ ) and the hexane extract of leaves ( $\mathrm{IC}_{50}: 24.90 \pm 0.02 \mu \mathrm{g} / \mathrm{mL}$ ) (Table 5).

\section{Discussion and Conclusion}

In the present study, results from our phytochemical analysis revealed that the chloroform extract of leaves of

Table 3. DPPH radical scavenging activity at $10 \mu \mathrm{g} / \mathrm{mL}$ of extract.

\begin{tabular}{cc}
\hline Extracts & \% DPPH radical scavenging \\
\hline BH & $2.30 \pm 0.02$ \\
BC & $27.10 \pm 0.01$ \\
BE & $76.70 \pm 0.02$ \\
LH & $6.20 \pm 0.02$ \\
LC & $31.20 \pm 0.01$ \\
LE & $46.60 \pm 0.02$ \\
AA & $97.60 \pm 0.00$ \\
GA & $91.50 \pm 0.01$ \\
QC & $81.60 \pm 0.01$ \\
\hline
\end{tabular}

BH: bark hexane extract, BC: bark chloroform extract, BE: bark ethanol extract, LH: leaf hexane extract, LC: leaf chloroform extract, LE: leaf ethanol extract, AA: Ascorbic Acid, GA: Gallic Acid, QC: Quercetin.

Table 4. Concentration of extract at DPPH radical scavenging activity $50 \%\left(\mathrm{IC}_{50}\right)$.

\begin{tabular}{cc}
\hline Extracts & DPPH IC $_{50}(\mu \mathrm{g} / \mathrm{mL})$ \\
\hline BH & $289.70 \pm 0.02$ \\
BC & $37.50 \pm 0.02$ \\
BE & $1.90 \pm 0.01$ \\
LH & $179.90 \pm 0.02$ \\
LC & $19.90 \pm 0.01$ \\
LE & $11.30 \pm 0.02$ \\
AA & $0.60 \pm 0.01$ \\
GA & $1.50 \pm 0.02$ \\
QC & $1.00 \pm 0.01$ \\
\hline
\end{tabular}

BH: bark hexane extract, BC: bark chloroform extract, BE: bark ethanol extract, LH: leaf hexane extract, LC: leaf chloroform extract, LE: leaf ethanol extract, AA: Ascorbic Acid, GA: Gallic Acid, QC: Quercetin and IC $\mathrm{C}_{50}$ : concentration where $50 \%$ inhibition of the DPPH radical is obtained. 




Figure 2. DPPH radical scavenging activity (\%) versus concentration $(\mu \mathrm{g} / \mathrm{mL})$. BH: bark hexane extract, BC: bark chloroform extract, BE: bark ethanol extract, LH: leaf hexane extract, LC: leaf chloroform extract, LE: leaf ethanol extract, AA: Ascorbic Acid, GA: Gallic Acid, QC: Quercetin.

Table 5. Antioxidant activity of extract at $50 \%$ Inhibition of $\beta$-Carotene $\left(\mathrm{IC}_{50}\right)$.

\begin{tabular}{cc}
\hline Extracts & $50 \%$ Inhibition of $\beta$-Carotene $\left(\mathrm{IC}_{50}\right)(\mu \mathrm{g} / \mathrm{mL})$ \\
BH & $50.70 \pm 0.02$ \\
BC & $49.50 \pm 0.02$ \\
BE & $9.90 \pm 0.01$ \\
LH & $24.90 \pm 0.02$ \\
LC & $48.90 \pm 0.01$ \\
LE & $24.30 \pm 0.02$ \\
AA & $9.60 \pm 0.01$ \\
GA & $10.50 \pm 0.02$ \\
QC & $25.10 \pm 0.01$ \\
\hline
\end{tabular}

BH: bark hexane extract, BC: bark chloroform extract, BE: bark ethanol extract, LH: leaf hexane extract, LC: leaf chloroform extract, LE: leaf ethanol extract, AA: Ascorbic Acid, GA: Gallic Acid, QC: Quercetin.

Melodinus eugeniifolus accumulate substantial amounts of alkaloids, flavonoids, sterols, steroids, saponins and cardiac glycosides, which could be well correlated with the activities measured.

Comparing with the three different assays, the FRAP assay was employed to estimate the antioxidant capacity of the samples in vitro. In the DPPH radical scavenging assay, antioxidants react with DPPH, and convert it to the yellow coloured a, a-diphenyl- $\beta$-picryl hydrazine. The degree of discolouration indicates the radical-scavenging potential of the sample. The $\beta$-Carotene bleaching method is based on the loss of the yellow colour of b-carotene due to its reaction with radicals which are formed by linoleic acid oxidation in an emulsion. The rate of $\beta$-carotene bleaching can be slowed down in the presence of antioxidants.

The antioxidant activity reflected by the FRAP, DPPH, and $\beta$-carotene bleaching assay were clearly observed in the ethanol extracts of bark and leaves among the six crude extracts of Melodinus eugeniifolus. Results were followed by the chloroform extract of barks and leaves. Hexane extract of barks and leaves had the lowest result 
in antioxidant activity tests.

We shall conduct further work to isolate the antioxidant and antibacterial constituents of the plant and evaluate their minimum inhibitory concentration (MIC). Quantitative phytochemical analysis of the crude extracts will also be proceeded.

\section{References}

[1] Barreira, J., Ferreira, I., Oliveira, M. and Pereira, J. (2008) Antioxidant Activities of the Extracts from Chestnut Flower, Leaf, Skins and Fruit. Food Chemistry, 107, 1106-1113. http://dx.doi.org/10.1016/j.foodchem.2007.09.030

[2] de Medeiros, J.M.D., Macedo, M., Contancia, J.P., Nguyen, C., Cunningham, G. and Miles, D.H. (2000) Zulu Medicinal Plants with Antibacterial Activity. Journal of Ethnopharmacology, 69, 157-165.

[3] Othman, M., Loh, H.S., Wiart, C., Khoo, T.J., Lim, K.H. and Ting, K.N. (2011) Optimal Methods for Evaluating Antimicrobial Activities from Plant Extracts. Journal of Microbiological Methods, 84, 161-166. http://dx.doi.org/10.1016/j.mimet.2010.11.008

[4] Jayaraman, P., Sakharkar, M.K., Lim, C.S., Tang, T.H. and Sakharkar, K.R. (2010) Activity and Interactions of Antibiotic and Phytochemical Combinations against Pseudomonas Aeruginosa in Vitro. International Journal of Biological Sciences, 6, 556-568. http://dx.doi.org/10.7150/ijbs.6.556

[5] Kang M.-H., Lee, M.S., Choi, M.K., Min, K.S. and Shibamoto, T. (2012) Hypoglycemic Activity of Gymnema Sylvestre Extracts on Oxidative Stress and Antioxidant Status in Diabetic Rats. Journal of Agricultural and Food Chemistry, 60, 2517-2524. http://dx.doi.org/10.1021/jf205086b

[6] Kamalinejad, M., Mojab, F., Ghaderi, N. and Vahidipour, H.R. (2003) Phytochemical Screening of Some Species of Iranian Plants. Iranian Journal of Pharmacertical Research, 2, 77-82.

[7] Satyajit, D.S. and Alexander, I.G. (2006) Extraction of Plant Secondary Metabolites. In: Satyajit, D.S. and Alexander, I.G., Eds., Natural Products Isolation, 2nd Edition, Natural Products Isolation, 339-342.

[8] Benzie, I.F.F. and Strain, J.J. (1996) The Ferric Reducing Ability of Plasma (FRAP) as a Measure of “Antioxidant Power”: The FRAP Assay. Analytical Biochemistry, 239, 70-76. http://dx.doi.org/10.1006/abio.1996.0292

[9] Alothman, M., Bhat, R. and Karim, A.A. (2009) Antioxidant Capacity and Phenolic Content of Selected Tropical Fruits from Malaysia, Extracted with Different Solvents. Food Chemistry, 115, 785-788. http://dx.doi.org/10.1016/j.foodchem.2008.12.005

[10] Juan-Badaturuge, M., Habtemariam, S. and Thomas, M.J.K. (2011) Antioxidant Compounds from a South Asian Beverage and Medical Palnt, Cassia Auriculata. Food Chemistry, 125, 221-225. http://dx.doi.org/10.1016/j.foodchem.2010.08.065

[11] Velioglu, Y.S., Mazza, G., Gao, L. and Oomah, B.D. (1998) Antioxidant Activity and Total Phenolics in Selected Fruits, Vegetables, and Grain Products. Journal of Agricultural and Food Chemistry, 46, 4113-4117. http://dx.doi.org/10.1021/jf9801973

[12] Lu, Y.R. and Foo, L.Y. (2000) Antioxidant and Radical Scavenging Activities of Polyphenols from Apple Pomace. Food Chemistry, 68, 81-85. http://dx.doi.org/10.1016/S0308-8146(99)00167-3

[13] Blois, M.S. (1958) Antioxidant Derterminations by the Use of a Stable Free Radical. Nature, 181, 1199-1200.

http://dx.doi.org/10.1038/1811199a0 
Scientific Research Publishing (SCIRP) is one of the largest Open Access journal publishers. It is currently publishing more than 200 open access, online, peer-reviewed journals covering a wide range of academic disciplines. SCIRP serves the worldwide academic communities and contributes to the progress and application of science with its publication.

Other selected journals from SCIRP are listed as below. Submit your manuscript to us via either submit@scirp.org or Online Submission Portal.
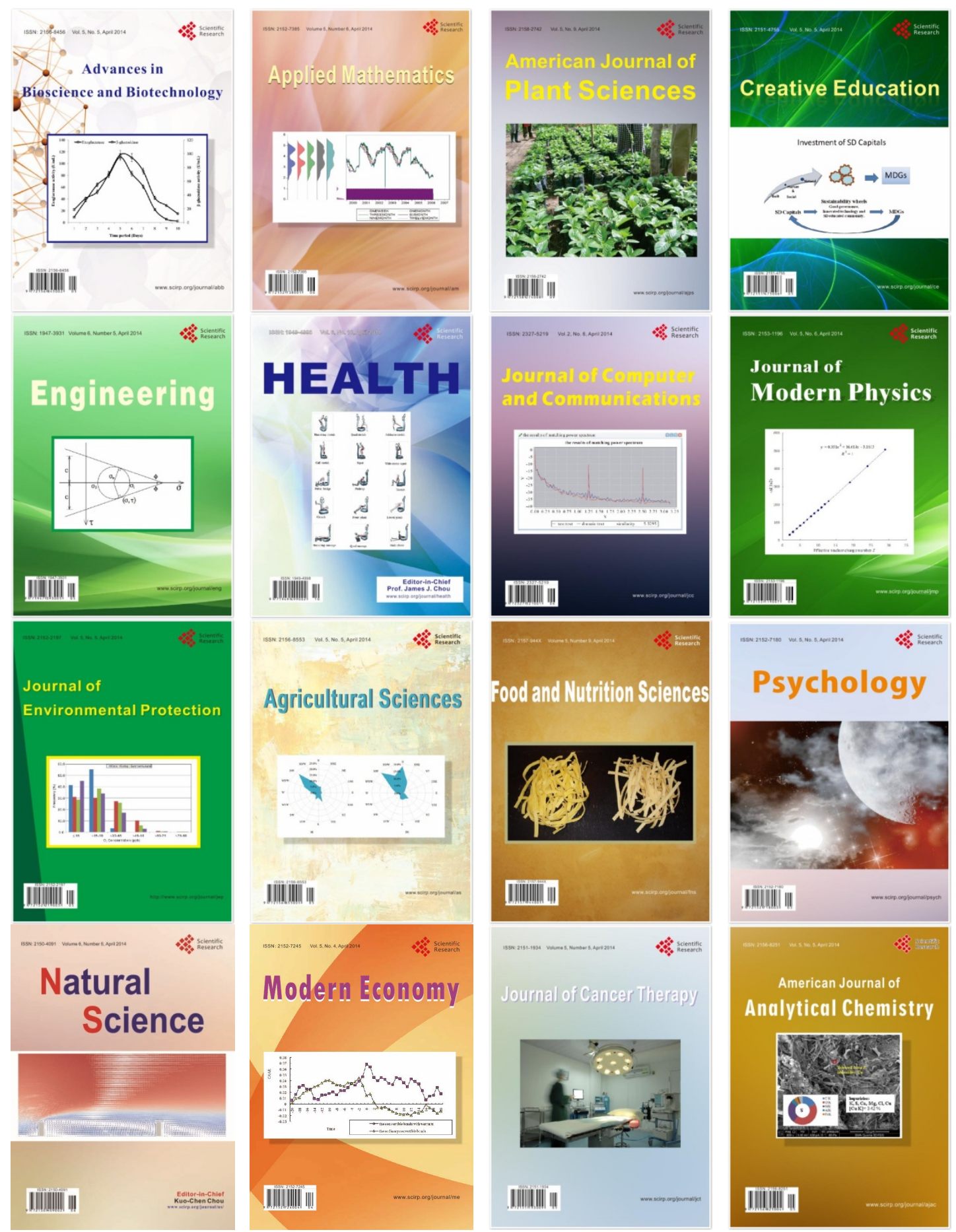